\title{
A Review of Advances in Carpal Tunnel Release

\author{
Logan $\mathrm{McCool}^{1}$, Michel Kliot${ }^{2}$, Danqing Guo ${ }^{3}$, Danzhu Guo ${ }^{3}$ \\ 'Department of Rehabilitation Medicine, University of Minnesota School of Medicine, Minneapolis MN 55455, USA \\ ${ }^{2}$ Department of Neurosurgery, Stanford University School of Medicine, Palo Alto, CA 94304, USA \\ ${ }^{3}$ BayCare Clinic, Green Bay, WI 54303, USA
}

\section{Article Info}

\section{Article Notes}

Received: September 01, 2017

Accepted: November 27, 2017

\section{${ }^{*}$ Correspondence:}

Dr. Logan McCool, Department of Rehabilitation Medicine University of Minnesota School of Medicine, Minneapolis MN 55455, USA, Email: mccool@umn.edu

(c) $2017 \mathrm{McCool} \mathrm{L}$. This article is distributed under the terms of the Creative Commons Attribution 4.0 International License

\section{ABSTRACT}

There have been many advances in recent years in peripheral nerve releases and most notably those involving median nerve entrapment at the wrist. This mini-review article focuses on the advances within the past five years in minimally, percutaneous, and ultra-minimally invasive techniques for carpal tunnel release. The progress in these surgical techniques has been made in part by the improvements in real time sonographic imaging. With each surgical technique, we look at the pre-clinical and clinical data and any complications from or limitations with these procedures. It is our aim with this article to spark discussion and spur innovation regarding ultrasound guided carpal tunnel release that can be applied to other peripheral nerve entrapments.

In the past five years, the surgical techniques to perform carpal tunnel release continue to advance. Among these surgical techniques is a growing trend towards less invasive methods and increased utilization of ultrasound guidance. In the literature, the list of methods includes open release, endoscopic release, minimally invasive release, percutaneous release, and ultra-minimally invasive release. These progressively less invasive techniques take advantage of the major improvements in both ultrasound image quality and real-time definition. This mini-review examines various surgical techniques involving minimally invasive, percutaneous, and ultra-minimally carpal tunnel release with emphasis on the development of techniques that are increasingly less invasive and more reliant on high-quality ultrasound imaging.

\section{MANOS}

In 2012, McCormack et al. performed 52 carpal tunnel releases using the MANOS device guided by a nerve stimulator ${ }^{1}$. In this study, the 2.1 millimeter MANOS device is passed through the carpal tunnel and a serrating wire is used to transect the transverse carpal ligament. In two follow-up case series examining a total of 6 patients, the MANOS surgical release technique was documented to be improved by utilizing ultrasound guidance ${ }^{2,3}$. Despite these developments, several complications have been documented.

\section{Complications}

Six patients had inadvertent skin lacerations at the entry and exit point. Two patients were treated with oral antibiotics for wrist puncture site redness and swelling which resolved. One had persistent wrist swelling for 3 months. One had a pulling sensation in the index and long fingers which resolved. One had dorsal thumb numbness which resolved at 3 months. Four patients had poor outcomes. Of these poor outcomes, 
one patient had persistent hand numbness and tingling 2 weeks after surgery and had an open exploration within one month that showed incomplete release of the distal third of the transverse carpal tunnel ligament.

"V" blade

In 2012, de la Fuenta et al. described the use of a "V"shaped scalpel used in the surgical release of the transverse carpal ligament. This cadaveric study of twenty specimens requires an initial transverse incision to insert a blunt probe with a "U"-shaped trough allowing for confirmation of the distal border of the flexor retinaculum. Then, the " $V$ "-shaped meniscotome, with a $5 \mathrm{~mm}$ gap between blades, is inserted and used to transect the transverse carpal ligament. In this study, there was complete release of the transverse carpal ligament and no injuries to the neurovascular bundles although one specimen required a second pass of the "V"shaped blade to completely transect the flexor retinaculum 4 .

\section{Percutaneous Needle Release}

McShane et al. reported in 2012 a surgical release technique whereby an 18-gauge needle is used to repeatedly fenestrate the transverse carpal ligament ulnar to and parallel with the median nerve. Post-procedure betamethasone and lidocaine were then administered. Thirty-six patients received this procedure in this retrospective preliminary study. With a response rate of less than $50 \%$, eighty-four percent of patients stated that they received satisfactory results ${ }^{5}$.

\section{Hook Knife}

In 2014 and 2015, Chern et al. describe a method of transecting the transverse carpal ligament using a hook knife. In the cadaveric study, 18 of 20 specimens were completely released with no neurovascular bundle injuries. This preclinical study was followed up with a preliminary case series of 91 patients. During this prospective case series, two cases were deemed unsatisfactory including one with moderate wrist pain and one with recurrence of carpal tunnel syndrome. One major limitation noted by the authors was the advanced skill required in performing ultrasound guidance $\mathrm{e}^{6,7}$.

\section{SX-One MicroKnife ${ }^{\mathrm{TM}}$}

In 2016, a new company, Sonex Health, developed the SX-One MicroKnife ${ }^{\mathrm{TM}}$. This procedure begins with sonographic visualization of relevant anatomic structures. The SX-One MicroKnife ${ }^{\mathrm{TM}}$ is inserted into the wrist through a 4-5 mm micro-incision. Protective bumpers are inflated to create a safe zone between the blade and the nearby tendons and neurovascular structures. The transverse carpal ligament is cut and then the blade is returned to its inactive position. The initial incision may be closed with an adhesive bandage, surgical glue, sutures or stitches if necessary. Approximately 70 cases have been performed using this method without complications as reported in the Sonex Health newsletter ${ }^{8}$.

\section{CarpX}

In 2017, PAVmed's CarpX ${ }^{\mathrm{TM}}$ applied to gain clearance from the FDA according to a June 2016 press release. The CarpX $^{\mathrm{TM}}$ is a balloon catheter with an integrated bipolar radiofrequency cutting electrode. It is guided into the carpal tunnel percutaneously over a guidewire without an open surgical incision. Positioning is confirmed by ultrasound and similar to the SX-One MicroKnife ${ }^{\mathrm{TM}}$ a protective balloon is inflated which protects vital structures from the cutting electrodes. These radiofrequency electrodes are then used to cut the transverse carpal ligament. In 2016, a non-peer reviewed press release reported completion of a preclinical study with an aim to publish in a peer reviewed journal. This press release reports that of the 14 patients, all transverse carpal ligaments were cut cleanly and without cauterization or injury to vital structures ${ }^{9}$.

\section{Thread Carpal Tunnel Release (TCTR)}

Recently, Guo et al. described a method of releasing the transverse carpal ligament using a nonserrating thread. The thread carpal tunnel release is a surgical technique involving a non-serrating, echogenic metal thread that is capable of being looped around the transverse carpal ligament and transecting this ligament ${ }^{10-12}$.

\section{Clinical outcomes}

To date, there have been 492 hands operated in the office with local anesthesia (Table 1). There were no neurovascular complications with up to 28 months of follow-up. Significant relief of symptoms is noted within 24 hours in most cases. Patients with office jobs are able to return to work on postoperative day 1 , and those with jobs involving more vigorous manual activities return to work in about two weeks ${ }^{12}$.

\section{What are the steps in performing the procedure?}

This multi-step procedure involves first identifying sonographic landmarks such as the proximal and distal boundaries of the transverse carpal ligament and palmar fascia; the recurrent motor branch to the thenar muscles; the Berrittini sensory nerve when present; the third digital nerve; and the superficial palmar arch artery. After sonographic identification of these important structures to preserve and surface skin marks are made with a marking pen, then the second step involves guiding a spinal need beneath the transverse carpal ligament through the carpal tunnel under ultrasound guidance. This step is made easier by hydrodissection with $1 \%$ lidocaine under ultrasound guidance which prevents iatrogenic injuries to the median nerve or surrounding tendons. The third step involves 
Table 1:

\begin{tabular}{|c|c|c|c|c|c|c|}
\hline Name & Authors & Device & Skin incision & AD & Cases & Complications \\
\hline Manos & McCormack et al. 2012 & $2.1 \mathrm{~mm}$ serrating wire & $3 \mathrm{~mm}$ & $\begin{array}{l}\mathrm{NS} \\
\mathrm{U} / \mathrm{S}\end{array}$ & Clinical: 52 & $\begin{array}{l}6 \text { skin lacerations. } \\
\text { Four with poor outcomes. }\end{array}$ \\
\hline "V" blade & de la Fuenta et al. 2012 & "V" scalpel & NA & $\mathrm{U} / \mathrm{S}$ & Cadaver: 20 & One required second pass. \\
\hline $\begin{array}{l}\text { Percutaneous needle } \\
\text { release }\end{array}$ & McShane et al, 2012 & $\begin{array}{l}\text { 18-gauge needle fenes- } \\
\text { trate }\end{array}$ & None & $\mathrm{U} / \mathrm{S}$ & Clinical: 36 & $\begin{array}{l}\text { Response rate }<50 \% \text {. } \\
84 \% \text { satisfactory results. }\end{array}$ \\
\hline Hook Knife & Chern et al; 2014 \& 2015 & Hook knife & None & $\mathrm{U} / \mathrm{S}$ & $\begin{array}{l}\text { Cadaver: } 20 \\
\text { Clinical: } 91\end{array}$ & $\begin{array}{l}\text { One with moderate wrist pain. } \\
\text { One with recurrence of CTS. }\end{array}$ \\
\hline SX-One MicroKnife ${ }^{T M}$ & $\begin{array}{l}\text { Sonex Health, 2016, } \\
\text { Newsletter }\end{array}$ & $\begin{array}{l}\text { Balloon catheter with } \\
\text { central blade }\end{array}$ & $4-5 \mathrm{~mm}$ & $\mathrm{U} / \mathrm{S}$ & Clinical: 70 & None \\
\hline CarpX & $\begin{array}{l}\text { PAV meds, } 2016 \text { Press } \\
\text { Release }\end{array}$ & $\begin{array}{l}\text { Balloon catheter with RF } \\
\text { cutting electrode }\end{array}$ & None & $\mathrm{U} / \mathrm{S}$ & Cadaver: 14 & None \\
\hline $\begin{array}{l}\text { Thread Carpal Tunnel } \\
\text { Release (TCTR) }\end{array}$ & $\begin{array}{l}\text { Guo et al, 2015, 2016, } \\
2017\end{array}$ & $\begin{array}{l}\text { 18-gauge needle and } \\
\text { thread }\end{array}$ & None & $\mathrm{U} / \mathrm{S}$ & $\begin{array}{l}\text { Cadaver: } 35 \\
\text { Clinical: } 492\end{array}$ & No neurovascular complica \\
\hline
\end{tabular}

Description: NS: nerve stimulator; U/S: ultrasound

passing the thread through the spinal needle. After the metal thread is passed under the transverse carpal ligament, a second pass over the transverse carpal ligament occurs using the same entry and exit points from the initial pass. The thread is again passed through the spinal needle which when pulled taut forms a loop around the transverse carpal ligament. The ability to confirm the correct placement of the thread without looping unintended adjacent structures is made possible by ultrasound guidance and visualization. This confirm-then-cut method of ultra-minimally invasive surgery is important in preventing iatrogenic injuries.

\section{Future Studies}

The thread surgical release technique has been expanded from carpal tunnel release to trigger finger release. Ongoing investigations are pursuing the thread surgical release's clinical efficacy and safety in use for cubital tunnel release, tarsal tunnel release, plantar fascia release, release for DeQuervain's tenosynovitis, common peroneal nerve release, and fascial release for compartment syndrome and plantar fasciitis.

\section{Conclusion}

In conclusion, so far, only TCTR is the ultrasound guided ultra-minimally invasive procedure with multiple clinical and cadaveric studies published demonstrating both effectiveness and safety. This surgical technique has also been cross applied to other surgical releases such as trigger finger with similar excellent results ${ }^{13}$.

\section{Acknowledgment}

This research was funded jointly by the University of Minnesota Department of Physical Medicine and Rehabilitation and BayCare Health.

\section{References}

1. McCormack B, Bowen W, Gunther S, et al. Carpal tunnel release using the MANOS CTR system: Preliminary results in 52 patients. J Hand Surg Am. 2012; 37(4): 689-94.
2. Buncke G, McCormack B, Bodor M. Ultrasound-guided carpal tunnel release using the manos CTR system. Microsurgery. 2013; 33(5): 362-6.

3. Markison RE. Percutaneous ultrasound-guided MANOS carpal tunnel release technique. Hand. 2013; 8(4): 445-9.

4. de la Fuente J, Miguel-Perez MI, Balius R, et al. Minimally invasive ultrasound-guided carpal tunnel release: a cadaver study. J Clin Ultrasound [Internet]. 2013; 41(2): 101-7. Available from: http:// www.ncbi.nlm.nih.gov/pubmed/22965620

5. Mcshane JM, Slaff S, Gold JE, et al. Needle Release of the Carpal Tunnel for Treatment of Carpal Tunnel Syndrome Preliminary Report. 2012; 1341-9.

6. Chern TC, Kuo LC, Shao CJ, et al. Ultrasonographically Guided Percutaneous Carpal Tunnel Release: Early Clinical Experiences and Outcomes. Arthrosc J Arthrosc Relat Surg [Internet]. 2015; 31(12): 2400-10. Available from: http://linkinghub.elsevier.com/retrieve/ pii/S0749806315005344

7. Chern $\mathrm{TC}, \mathrm{Wu} \mathrm{KC}$, Huang $\mathrm{LW}$, et al. A Cadaveric and preliminary clinical study of ultrasonographically assisted percutaneous carpal tunnel release. Ultrasound Med Biol. 2014; 40(8): 1819-26.

8. Barnes D, Smith J. Milestone Reached - Dr. Marko Bodor Performs 50th Case! [Internet]. Sonex Health Newsletter. 2017 [cited 2017 Jan 1]. p. 1. Available from: http://myemail. constantcontact.com/Sonex-Health-completes-50th-case-. html?soid=1126046747952\&aid=noTptHw4EB4

9. Sandoval E. ADDING MULTIMEDIA PAVmed Successfully Completes CarpX $^{\mathrm{TM}}$ Pre-Clinical Study [Internet]. Business Wire. 2016 [cited 2017 Jan 1]. p. 1. Available from: http://www.businesswire.com/ news/home/20160622005383/en/ADDING-MULTIMEDIA-PAVmedSuccessfully-Completes-CarpX ${ }^{\mathrm{TM}}$-Pre-Clinical

10. Guo D, Guo D, Guo J, et al. A Cadaveric Study for the Improvement of Thread Carpal Tunnel Release. J Hand Surg Am [Internet]. 2016; 41(10): 1-7. Available from: http://linkinghub.elsevier.com/retrieve/ pii/S036350231630380X

11. Guo D, Tang Y, Ji Y, et al. A non-scalpel technique for minimally invasive surgery: percutaneously looped thread transection of the transverse carpal ligament. Hand. 2015; 10(1): 40-8.

12. Guo D, Guo D, Guo J, et al. A Clinical Study of the Modified Thread Carpal Tunnel Release (TCTR). Hand [Internet]. 2016; Available from: http://han.sagepub.com/lookup/doi/10.1177/1558944716668831

13. Guo D, Guo D, Guo J, etal. A Cadaveric Study of the Thread Trigger Finger Release. Hand [Internet]. 2017; 155894471769743. Available from: http://journals.sagepub.com/doi/10.1177/1558944717697433 